\title{
Current status of and strategies for hepatitis C control in South Korea
}

\author{
Beom Kyung Kim?', Eun Sun Jang², Jeong Han Kim³, Soo Young Park ${ }^{4}$, Song Vogue Ahn ${ }^{5}$, Hyung Joon Kim', \\ and Do Young Kim ${ }^{1}$
}

'Department of Internal Medicine, Yonsei University College of Medicine, Seoul; ${ }^{2}$ Department of Internal Medicine, Seoul National University Bundang Hospital, Seongnam; ${ }^{3}$ Department of Internal Medicine, Konkuk University School of Medicine, Seoul; ${ }^{4}$ Department of Internal Medicine, School of Medicine, Kyungpook National University, Daegu; ${ }^{5}$ Department of Preventive Medicine, Wonju College of Medicine, Yonsei University, Wonju; ' Department of Internal Medicine, College of Medicine, Chung-Ang University, Seoul, Korea

Chronic hepatitis $\mathrm{C}(\mathrm{CHC})$ is caused by hepatitis $\mathrm{C}$ virus (HCV) infection. HCV infection causes acute hepatitis, and the majority of those infected progress to chronic hepatitis, and some of them develop cirrhosis and hepatocellular carcinoma. Transmission of HCV is parenteral, and the major transmission routes include drug abuse, insecure injections or medical procedures, contaminated syringes or needles, sexual contact with an HCV-infected person, vertical infection of newborns by infected mothers, the transfusion of blood or blood products contaminated with viruses, and organ transplants. As no vaccine against $\mathrm{HCV}$ is available, $\mathrm{HCV}$ management involves blocking routes of transmission transmission, screening for $\mathrm{HCV}$ infection, and protecting liver disease progression by treatment. Highly potent oral direct antiviral agents are now available. Therefore, early detection through nation-wide screening program and appropriate treatment should be implemented to improve the quality of life of patients with HCV. Furthermore, for the effective HCV control in South Korea, The organization of an 'integrated national viral hepatitis control system' is desirable. (Clin Mol Hepatol 2017;23:212-218)

Keywords: Hepatitis C virus; Status; Control

\section{INTRODUCTION}

Hepatitis C virus (HCV) infection causes chronic hepatitis in most patients, and some of them eventually develop cirrhosis or hepatocellular carcinoma. ${ }^{1}$ It is estimated that approximately $3 \%$ of the world's population are infected with HCV and chronic hepatitis C (CHC) accounts for about 15-20\% of all chronic liver disease in South Korea. Transmission of HCV is parenteral, and the major transmission routes include drug abuse, insecure injections or medical procedures, contaminated syringes or needles, sexual contact with an HCV-infected person, vertical infection of newborns by infected mothers, the transfusion of blood or blood products contaminated with viruses, and organ transplants. ${ }^{2} \mathrm{Be}$ tween 2015 and 2016, mass outbreaks of HCV occurred at several hospitals in Seoul and other provincial clinics, primarily due to reuse of disposable syringes.

As an effective HCV vaccine has not yet been discovered, public health considerations underscore the need to develop both an understanding of the national epidemiology of HCV infection and a preventive strategy to block routes of this condition.

\section{Abbreviations:}

CHC, chronic hepatitis C; ElA, enzyme immunoassay; HCV, hepatitis C virus; HIV, human Immunodeficiency Virus; ICER, incremental cost-effectiveness ratio; QALY, quality-adjusted life year; RNA, ribonucleic acid

\section{Corresponding author : Do Young Kim}

Department of Internal Medicine, Yonsei University College of Medicine, 50-1 Yonsei-ro, Seodaemun-gu, Seoul 03722, Korea

Tel: +82-2-2228-1930, Fax: +82-2-393-6884

E-mail:dyk1025@yuhs.ac

http://orcid.org/0000-0002-8327-3439 


\section{EPIDEMIOLOGY}

\section{Routes of transmission}

Transmission of HCV is parenteral, and a screening test for blood donors was introduced in 1991. Therefore, transmission via transfusion was not a major route of infection after 1992. ${ }^{3-5}$ The use of illicit drugs is a well-known risk factor for HCV infection; indeed, the proportion of HCV infection among drug users is approximately $80 \%$ in South Korea. ${ }^{5,6}$ However, a nationwide prospective cohort study that included 1,173 subjects revealed that the proportion of drug abuse was $5 \%$. $^{7}$ Thus, identification of other routes of transmission is necessary. According to a study of 207 patients with chronic HCV infection, the risk factors for HCV infection include older age, needle-stick injury, dental procedures, multiple sex partners ( $\geq 4$ ), blood transfusion before 1991, and surgery. ${ }^{8}$ A comparative study of 1,173 HCV patients and 534 controls in five university hospitals between 2007 and 2011 in South Korea reported several independent risk factors for infection, including use of illicit drugs, needle-stick injury, transfusion before 1995, tattoo, and age. ${ }^{7}$

\section{Prevalence in adult health-check examinees}

The estimated age-standardized prevalence of anti-HCV in adult

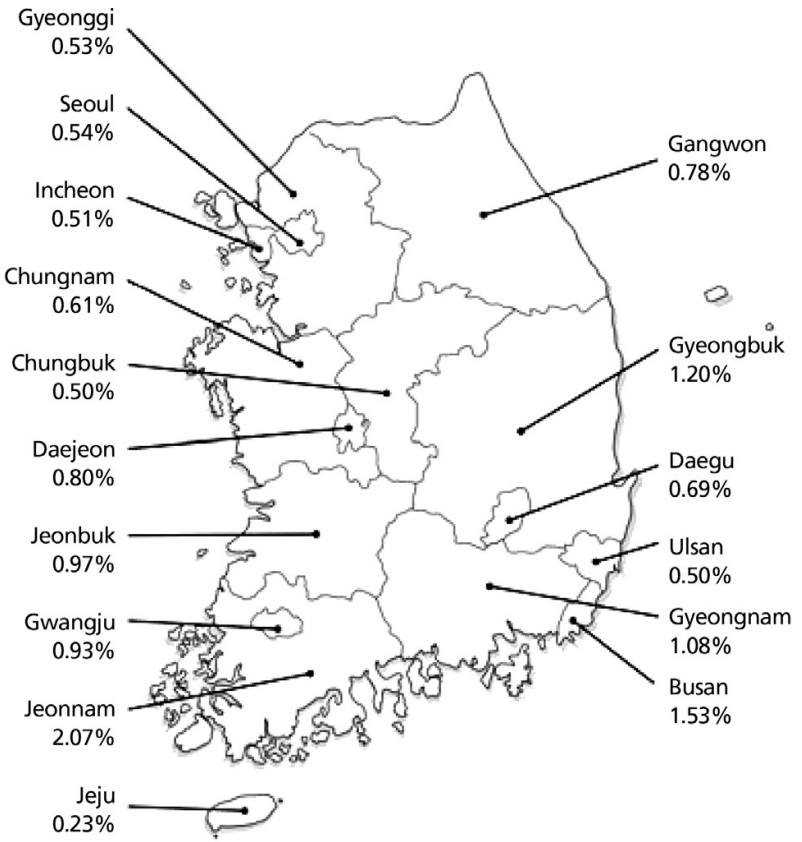

Figure 1. Map of South Korea showing age and sex-adjusted anti-HCV seroprevalence in each area. $^{3}$ health-check examinees $>40$ years of age is $1.29 \%$ (95\% confidence interval, 1.12-1.48) according to a collective study of health-check examinees from Seoul, Ulsan, Jeollanam-do, and Daegu between 1995 and 2000.,9-12 In 2009, the prevalence of anti-HCV was $0.78 \%$ in 291,314 patients older than 20 years who underwent health check-up at 29 health examination centers using the 3rd generation enzyme immunoassay (EIA) after adjusting for age, sex, and area. In that study, the prevalence of anti-HCV was higher in females $(0.83 \%)$ than in males $(0.75 \%)$ and increased with age (20-29 years, $0.34 \% ; 30-39$ years, $0.41 \% ; 40-49$ years, $0.60 \%$; $50-59$ years, $0.80 \%$; $60-69$ years, $1.53 \%$; and $\geq$ 70 years, $2.31 \%$ ). ${ }^{3}$ Additionally, the anti-HCV prevalence varied geographically; in comparison with the prevalence of 0.50-1.20\% in most regions, including Seoul and Gyeonggi-do, the prevalence in Pusan and Jeollanam-do were $1.53 \%$ and $2.07 \%$, respectively. The Jeju Special Self-Governing Province had the lowest prevalence, $0.23 \%$ (Fig. 1). $^{3}$

The Korea National Health and Nutrition Examination Survey has included anti-HCV testing since 2012. From 2012 to 2014, the prevalence of hepatitis $C$ antibody positivity was $0.7 \%$ among 15,795 subjects aged $\geq 19$ years, which was similar to that in the 2009 National Health Survey (Table 1). The prevalence was low $(0.4 \%)$ in subjects with a high level of income. ${ }^{13}$

According to the infectious disease statistics of the Korea Center for Disease Control, ${ }^{14}$ the average number of reports of hepatitis C infection in 2015 was 4,205 (standard deviation, 331.1). Up to the end of August 2016, 4,003 cases had been reported; therefore, the number of reports has increased within the past 2 years (Table 2). However, according to the 2014 annual surveillance report of the Korea Center for Disease Control, ${ }^{15}$ the number of reports per institution has remained relatively stable, at 43.2 in 2011 and 35 in 2014 (Fig. 2).

\section{Prevalence of anti-HCV in high-risk groups}

High-risk groups for HCV infection include people who inject drugs, patients under hemodialysis, and those with human immunodeficiency virus (HIV) infection, hemophilia, and leprosy. However, the majority of studies of the prevalence of HCV in these groups were conducted prior to 2000; few studies were performed thereafter. ${ }^{2}$

According to a 1997 survey, the domestic anti-HCV prevalence among intravenous drug users was 79.2\%. ${ }^{16}$ From 2007 to 2010, the rates of hepatitis $C$ antibody positivity and HCV ribonucleic acid (RNA) positivity among the HCV RNA-positive subjects 
Table 1. The prevalence of hepatitis C antibody positivity from the Korea National Health and Nutrition Examination Survey for the period from 2012 to 2014 from the Korea National Health and Nutrition Examination Survey (unit: \%)

\begin{tabular}{|c|c|c|c|c|c|c|c|c|c|}
\hline \multirow[b]{2}{*}{$\geq 19$ years old } & \multirow{2}{*}{$\begin{array}{c}\mathbf{n} \\
15,795\end{array}$} & \multicolumn{2}{|c|}{$\begin{array}{c}\text { Prevalence } \\
\text { (standardized error) }\end{array}$} & \multirow{2}{*}{$\begin{array}{c}\mathbf{n} \\
6,806\end{array}$} & \multicolumn{2}{|c|}{$\begin{array}{c}\text { Prevalence } \\
\text { (standardized error) }\end{array}$} & \multirow{2}{*}{$\begin{array}{c}\mathbf{n} \\
8,989\end{array}$} & \multicolumn{2}{|c|}{$\begin{array}{c}\text { Prevalence } \\
\text { (standardized error }\end{array}$} \\
\hline & & 0.7 & $(0.1)$ & & 0.6 & $(0.1)$ & & 0.8 & $(0.1)$ \\
\hline$\geq 30$ years old & 13,915 & 0.8 & $(0.1)$ & 6,011 & 0.7 & $(0.1)$ & 7,904 & 0.9 & $(0.1)$ \\
\hline \multicolumn{10}{|l|}{ Age (years) } \\
\hline $10-18$ & 1,969 & 0.1 & $(0.1)$ & 1,045 & 0.1 & $(0.1)$ & 924 & 0.1 & $(0.1)$ \\
\hline $19-29$ & 1,880 & 0.2 & $(0.1)$ & 795 & 0.1 & $(0.1)$ & 1,085 & 0.3 & $(0.2)$ \\
\hline $30-39$ & 2,818 & 0.3 & $(0.1)$ & 1,208 & 0.2 & $(0.1)$ & 1,610 & 0.3 & $(0.2)$ \\
\hline $40-49$ & 2,955 & 0.5 & $(0.2)$ & 1,287 & 0.6 & $(0.3)$ & 1,668 & 0.5 & $(0.2)$ \\
\hline $50-59$ & 3,125 & 0.9 & $(0.2)$ & 1,302 & 0.8 & $(0.2)$ & 1,823 & 1.0 & $(0.3)$ \\
\hline $60-69$ & 2,729 & 1.3 & $(0.2)$ & 1,234 & 1.2 & $(0.3)$ & 1,495 & 1.3 & $(0.3)$ \\
\hline $70+$ & 2,288 & 1.9 & $(0.4)$ & 980 & 1.4 & $(0.4)$ & 1,308 & 2.2 & $(0.5)$ \\
\hline \multicolumn{10}{|c|}{ Residence (standardized) } \\
\hline Dong & 14,347 & 0.5 & $(0.1)$ & 6,273 & 0.4 & $(0.1)$ & 8,074 & 0.5 & $(0.1)$ \\
\hline Eub/Myun & 3,417 & 0.9 & $(0.3)^{*}$ & 1,578 & 0.9 & $(0.3)^{*}$ & 1,839 & 0.9 & $(0.4)^{*}$ \\
\hline \multicolumn{10}{|c|}{ Income (standardized) } \\
\hline Low & 4,277 & 0.6 & $(0.1)$ & 1,895 & 0.5 & $(0.1)^{*}$ & 2,382 & 0.8 & $(0.2)^{*}$ \\
\hline Mid-low & 4,455 & 0.6 & $(0.1)$ & 1,984 & 0.5 & $(0.1)^{*}$ & 2,471 & 0.6 & $(0.1)$ \\
\hline Mid-high & 4,442 & 0.6 & $(0.1)$ & 1,954 & 0.5 & $(0.2)^{*}$ & 2,488 & 0.7 & $(0.2)^{*}$ \\
\hline High & 4,437 & 0.4 & $(0.1)$ & 1,952 & 0.4 & $(0.1)^{*}$ & 2,485 & 0.5 & $(0.1)^{*}$ \\
\hline
\end{tabular}

*Reconstructed from table 3-29 of National Health Statistics 2014.

Table 2. Report of hepatitis $C$ by the sample surveillance within the last 4 years ${ }^{14}$

\begin{tabular}{lccc}
\hline \multirow{2}{*}{ Years } & \multicolumn{3}{c}{ Cases of hepatitis C } \\
\cline { 2 - 4 } & Total & Male & Female \\
\hline 2013 & 3,703 & 1,832 & 1,871 \\
2014 & 4,126 & 2,043 & 2,083 \\
\hline 2015 & 4,609 & 2,217 & 2,392 \\
\hline 2016 (up to August) & 4,003 & 1,911 & 2,092 \\
\hline
\end{tabular}

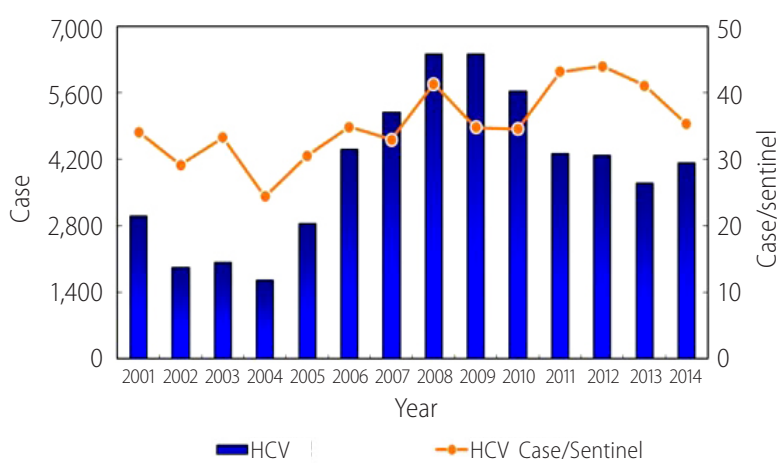

Figure 2. Status of reporting of hepatitis C virus infection by year according to sample surveillance. ${ }^{15}$ among 318 intravenous drug abusers in South Korea were 48.4\% and $98.1 \%$, respectively. ${ }^{17}$ The anti-HCV prevalence was $5.9-$ $14.7 \%$ in previous studies of $>200$ patients with chronic kidney disease who underwent hemodialysis between 1997 and 1998. ${ }^{18,19}$ According to the 2014 report of the Korean Society of Nephrology, ${ }^{20}$ the hepatitis C antibody positivity rate was $2.2 \%$ and was correlated with the duration of hemodialysis. The co-infection of HCV and HIV was relatively high, which accounts for 5.0-6.3\% of HIV infected patients in South Korea. ${ }^{21-23}$ According to a 2002 report, the anti-HCV prevalence in hemophilia patients was $42.3 \%$, and the risk of infection was correlated with age and 
Table 3. The number of medical institutes obliged to report cases of HCV infection to health authorities and the number of the cases ${ }^{15}$

\begin{tabular}{|c|c|c|c|c|c|c|c|c|c|c|c|c|c|}
\hline & 2002 & 2003 & 2004 & 2005 & 2006 & 2007 & 2008 & 2009 & 2010 & 2011 & 2012 & 2013 & 2014 \\
\hline No. of medical institutes & 677 & 728 & 788 & 833 & 877 & 873 & 889 & 1,035 & 1,024 & 167 & 170 & 167 & 175 \\
\hline No. of cases & 1,927 & 2,033 & 1,657 & 2,843 & 4,401 & 5,179 & 6,407 & 6,406 & 5,629 & 4,316 & 4,272 & 3,703 & 4,126 \\
\hline
\end{tabular}
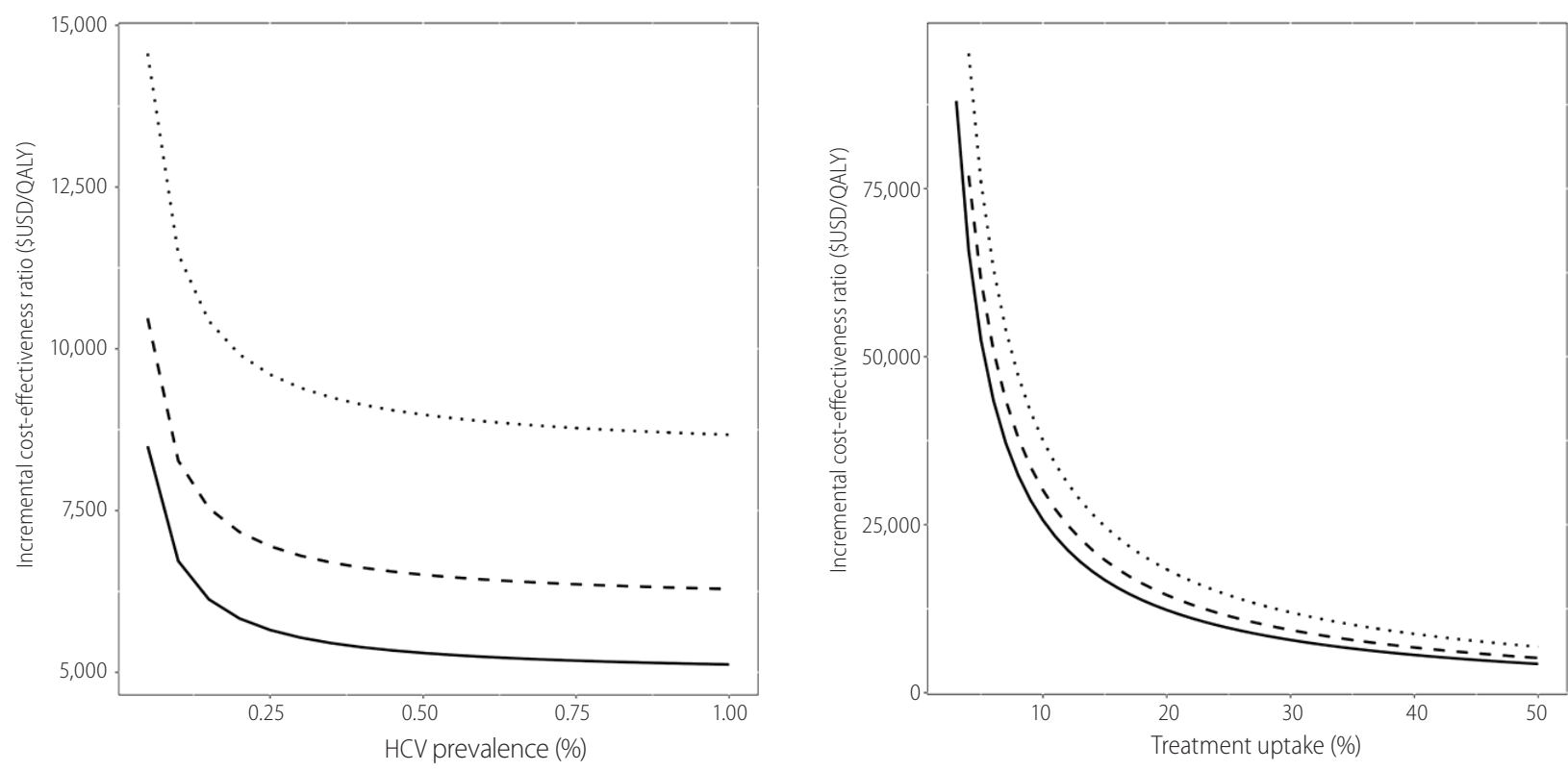

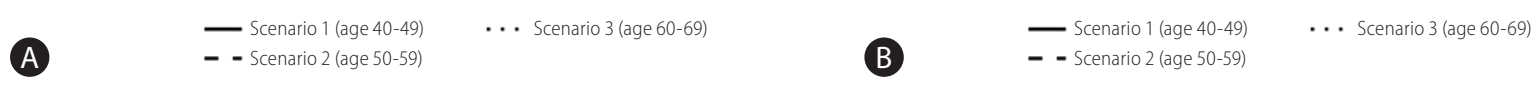

Figure 3. The relationship between the cost-effectiveness of screening and treatment, the prevalence of HCV amongst the general population and the rate of therapy uptake post diagnosis. ${ }^{28}$

severity of hemophilia. ${ }^{24}$ In their 2012 annual report, the Korea Hemophilia Foundation reported that the rates of anti-HCV antibody positivity and HCV RNA positivity were $20.0 \%$ and $5.5 \%$, respectively. ${ }^{25}$ The anti-HCV prevalence tested by second-generation EIA was $67.7 \%$ in 1997; $82 \%$ of these individuals were immunoblot-positive. ${ }^{26}$ According to 2009 data, the anti-HCV prevalence and the HCV RNA positivity rate among those anti-HCV positive were $35.1 \%$ and $88 \%$, respectively. ${ }^{27}$

\section{Strategies for HCV control in South Korea}

As seen in the recent 'HCV infection events' in the Dana and Hanyang clinics, there is a problem with the management and inspection of the risk of viral hepatitis transmission in front-line medical institutes. Unlike hepatitis $B$, hepatitis $C$ can be cured by antiviral treatment, and the sustained virologic response rate of this treatment is very high with few side-effects. Therefore, in Korea, if suspected, a hepatitis $C$ test should be performed and treated early. Therefore, it is necessary to evaluate the national management system for hepatitis $C$, and a system of detection and reporting similar to those implemented by advanced countries should be developed.

At present, 186 medical institutions subject to the government's selected monitoring are obliged to report cases of HCV to health authorities (Table 3). Therefore, HCV cases in medical institutes other than the 186 designated institutes can be missed. In November 2016, a new law which designated hepatitis $C$ as a group 3 nationally notifiable infectious disease and mandated a total reporting system for HCV infection had been passed. This new law will come into effect on June. $3^{\text {rd }}$ in 2017.

National screening for HCV infection has not yet been implemented in South Korea, because its prevalence is relatively low compared to that of HBV infection. In contrast to HBV infection, HCV infection can be cured by administration of direct acting antivirals. Therefore, scholars believe that a national screening program for HCV should be implemented to facilitate prompt treatment. From the viewpoint of health economics, early treatment of $\mathrm{HCV}$ infection prior to progression of liver disease might reduce 
Table 4. The relationship between the timing of treatment post-diagnosis and the cost-effectiveness of a screening and treatment program ${ }^{28}$

\begin{tabular}{|c|c|c|c|}
\hline & \multicolumn{3}{|c|}{$\begin{array}{l}\text { Incremental results } \\
\text { (versus no screening and treatment) }\end{array}$} \\
\hline & Costs (\$USD, million) & QALYs & ICER (\$USD/QALY) \\
\hline \multicolumn{4}{|l|}{ Scenario 1 (Age 40-49) } \\
\hline Base case & 164.72 & 28,830 & 5,714 \\
\hline Treatment initiated over 3 years post-diagnosis & 163.91 & 29,641 & 5,530 \\
\hline Treatment initiated in first year post-diagnosis & 162.70 & 30,875 & 5,270 \\
\hline \multicolumn{4}{|l|}{ Scenario 2 (Age 50-59) } \\
\hline Base case & 156.47 & 22,865 & 6,843 \\
\hline Treatment initiated over 3 years post-diagnosis & 155.73 & 23,577 & 6,605 \\
\hline Treatment initiated in first year post-diagnosis & 154.63 & 24,674 & 6,267 \\
\hline \multicolumn{4}{|l|}{ Scenario 3 (Age 60-69) } \\
\hline Base case & 181.85 & 20,457 & 8,889 \\
\hline Treatment initiated over 3 years post-diagnosis & 181.06 & 21,202 & 8,540 \\
\hline Treatment initiated in first year post-diagnosis & 179.87 & 22,375 & 8,039 \\
\hline
\end{tabular}

ICER, incremental cost-effectiveness ratio; QALY, quality-adjusted life year; USD, United States Dollar.

the overall medical cost. One recent study used Markov modeling to assess the cost-effectiveness of antiviral treatment for patients in the general population diagnosed with hepatitis $C{ }^{28}$ In that study, regardless of risk factors, hepatitis screening tests for HCV in 40-, 50-, and 60-year-olds reduced the incidence of liver cirrhosis and liver cancer by inhibiting the progression of liver disease. One-time HCV screening and treatment in South Koreans aged $40-70$ years is likely to be highly cost-effective compared to the current practice not conducting screening. ${ }^{28}$ Screening resulted in the identification of 43,635 previously undiagnosed patients across all cohorts. One-time HCV screening and treatment was estimated to be cost-effective across all cohorts, and predicted incremental cost-effectiveness ratios (ICERs) ranged from $\$ 5,714$ to $\$ 8,889$ per quality-adjusted life year (QALY) gained. Incremental costs associated with screening, treatment, and disease management ranged from $\$ 156.47$ to $\$ 181.85$ million USD; lifetime costs-offsets associated with the avoidance of end-stage liver disease complications ranged from $\$ 51.47$ to $\$ 57.48$ million USD. ${ }^{28}$ The relationship among HCV prevalence, treatment uptake, and the cost-effectiveness of the screening and treatment program is shown in Fig. 3. Screening and treatment remained cost-effective at a $\$ 27,512 /$ QALY threshold across all scenarios in which HCV prevalence was at least $0.04 \%$. In the analysis using baseline HCV prevalence, screening remained cost-effective when treatment uptake was at least $11 \%, 12 \%$, and $15 \%$ in the $40-49$-year-old, 50-59-year-old, and 60-69-year-old cohorts, respectively. The relationship between the timing of treatment after diagnosis and its incremental costs and QALY gains is presented in Table 4. Across all scenarios, treating patients sooner after diagnosis was associated with reduced total cost and increased QALY gains compared to base case analyses in which patients were treated over a 5 -year time horizon. Decreasing the delay before treatment initiation increased cost-effectiveness estimates across all age groups.

Unlike Western countries, in which the major transmission route is illegal IV drug use, the prevalence of hepatitis $C$ in South Korea is high in the elderly population, especially in coastal areas. ${ }^{8}$ Additionally, the frequencies of a history of acupuncture, moxibustion, and tattooing were higher in patients with hepatitis C. Moreover, workers in dental clinics, Oriental clinics, acupuncture centers, and tattoo parlors had low levels of awareness of infection control and are not obliged to report HCV infection. In the past 2 years, the media has reported three outbreaks of infectious diseases originating in medical institutions. Such outbreaks are presumed to be due to syringe reuse. Therefore, members of the general population who do not have high-risk diseases (including HIV, hemophilia, leprosy, and chronic kidney disease) could be exposed to HCV infection in medical institutions in which invasive procedures are performed. Therefore, practical measures for infection control should be implemented in these institutes. Also, appropriate supervision by health authorities of medical institutions in which invasive procedures are performed is warranted. Education programs regarding the medical hazards of $\mathrm{CHC}$ and how to prevent transmission are necessary not only for the gener- 
al population but also for medical personnel, including physicians and paramedics.

Furthermore, establishment of an independent 'viral hepatitis sector' in Korea Center for Disease Control \& Prevention is recommended to implement a strategy for the management of viral hepatitis. As a control tower has paramount importance in providing health care strategy into practice, organization of an 'integrated national viral hepatitis control system' is proposed.

\section{CONCLUSION}

As no vaccine against HCV is available, HCV management involves blocking routes of transmission, screening for HCV infection, and preventing liver disease progression by treatment. Highly potent oral direct antiviral agents are now available. Therefore, early detection through national screening and appropriate treatment should be implemented to improve the quality of life of patients with HCV.

\section{Conflicts of Interest}

The authors have no conflicts to disclose.

\section{Funding support}

This research was supposed by a fund (4851-308-260-01) by Research of Korea Centers for Disease Control and Prevention.

\section{REFERENCES}

1. Suh DJ, Jeong SH. Current status of hepatitis C virus infection in Korea. Intervirology 2006;49:70-75.

2. Korean Association for the Study of the Liver. KASL clinical practice guidelines: management of hepatitis C. Clin Mol Hepatol 2016;22:76-139

3. Kim DY, Kim IH, Jeong SH, Cho YK, Lee JH, Jin YJ, et al. A nationwide seroepidemiology of hepatitis $C$ virus infection in South Korea. Liver Int 2013;33:586-594.

4. Shin HR, Kim JY, Ohno T, Cao K, Mozikami M, Risch H, et al. Prevalence of risk factors of hepatitis $C$ virus infection among Koreans in rural area of Korea. Hepatol Res 2000;17:185-196.

5. Kim YS, Ahn YO, Lee HS. Risk factors for hepatitis C virus infection among Koreans according to the hepatitis C virus genotype. J Korean Med Sci 2002;17:187-192.

6. Shin HR. Epidemiology of hepatitis C virus in Korea. Intervirology 2006;49:18-22.
7. Seong MH, Kil H, Kim YS, Bae SH, Lee YJ, Lee HC, et al. Clinical and epidemiological features of hepatitis $C$ virus infection in South Korea: a prospective, multicenter cohort study. J Med Virol 2013;85:1724-1733.

8. Kim JY, Cho J, Hwang SH, Kil H, Bae SH, Kim YS, et al. Behavioral and healthcare-associated risk factors for chronic hepatitis $C$ virus infection in Korea. J Korean Med Sci. 2012;27:1371-1377.

9. Jeong $T H$, Jeon TH. PCR prevalence and risk factors of hepatitis $C$ virus infection in the adult population of Ulsan. J Korean Acad Fam Med 1998;19:364-373.

10. Na HY, Park MH, Park KS, Sohn YH, Joo YE, Kim SJ. Geographic characteristics of positivity of anti - HCV and Chonnam province: survey data of 6, 790 health screenees. Korean J Gastroenterol 2001;38:177-184.

11. Park KS, Lee YS, Lee SG, Hwang JY, Chung WJ, Cho KB, et al. A study on markers of viral hepatitis in adults living in Daegu and Gyungbuk area. Korean I Gastroenterol 2003;41:473-479.

12. Seo WT, Lee SS. A study on positive rate of $\mathrm{HBs} A g, H B s \mathrm{Ab}$ and anti-HCV in Korean adults. Korean J Blood Transfus 1998;9:259272.

13. Ministry of Health and Welfare. Korea Centers for Disease Control and Prevention. Korea Health Statistics 2014: Korea National Health and Nutrition Examination Survey (KNHANES V1-2).

14. Korea Centers for Disease Control and Prevention. Disease web statistics system. <http://is.cdc.go.kr/dstat>. Accessed 2016. 8. 24.

15. Center for Disease Control \& Prevention (KO). 2014 Infectious diseases surveillance yearbook. Osong: Center for Disease Control \& Prevention, 2014.

16. Kim HS, Choo DH. Prevalence of hepatitis C, B and human immunodeficiency virus among drug users and chronic alcoholic patients in Korea. Korean J Med 1997;52:754-762.

17. Min JA, Yoon Y, Lee HJ, Choi J, Kwon M, Kim K, et al. Prevalence and associated clinical characteristics of hepatitis $B, C$, and HIV infections among injecting drug users in Korea. J Med Virol 2013:85:575-582.

18. Kim H, Kim KT, Yoo JH, Kim BI, Lee SJ, Lee EJ, et al. Prevalence and risk factors of hepatitis $\mathrm{C}$ virus infection in chronic hamodialysis patients (multi-center study). Korean J Med 1997;52:833-840.

19. Shin YH, Kim HK, Choi SD, Kim YS, Shin HS, Won YJ, et al. Prevalence of anti-HCV in hemodialysis patients in Taegu and Kyeongbuk. Korea. Korean J Med 1998;54:640-646.

20. ESRD Registry Committee, Korean Society of Nephrology. Current renal replacement therapy in Korea: Insan memorial dialysis registry, 2014. Kidney Res Clin Pract 2015:117-136.

21. Sherman KE, Rouster SD, Chung RT, Rajicic N. Hepatitis C virus prevalence among patients infected with human immunodeficiency virus: a cross-sectional analysis of the US adult AIDS clinical trials group. Clin Infect Dis 2002;34:831-837. 
22. Kim O, Kim SS, Park MS, Suh SD, Lee MW, Kim KS, et al. Seroprevalence of sexually transmitted viruses in Korean populations including HIV-seropositive individuals. Int J STD AIDS 2003;14:46-49.

23. Lee SH, Kim KH, Lee SG, Chen DH, Jung DS, Moon CS, et al. Trends of mortality and cause of death among HIV-infected patients in Korea, 1990-2011. J Korean Med Sci 2013;28:67-73.

24. Kim SY, Kook JH, Choi IS, Kim SJ, Kook H, Hwang TJ. Viral hepatitis and change of lymphocyte subpopulation in hemophiliacs in Chonnam KwangJu area. Korean J Blood Transfus 2002;13:43-51.
25. Korea Hemophilia Association. 2012 Korean hemophilia annual report. Seoul: Korea Hemophilia Association, 2012.

26. Choi SH. The prevalence of hepatitis C virus infection in leprous patients. Korean J Gastroenterol 1997;30:486-494.

27. Kim JP, Lee RH. Status of hepatitis C in Hansen's disease. Korean Lepr Bull 2009;42:55-66.

28. Kim DY, Han KH, Jun B, Kim TH, Park S, Ward T, et al. Estimating the cost-effectiveness of one-time screening and treatment for hepatitis C in Korea. PLoS One 2017;12:e0167770. 